\title{
The Impact of Power Reconstruction in the Era of Big Data
}

\author{
Jiancheng $\mathrm{Li}^{1}$ Jingjing $\mathrm{Du}^{2, *}$ \\ ${ }^{1}$ PhD student, School of Government, Beijing Normal University \\ ${ }^{2}$ Postgraduate of the School of Government, Beijing Normal University \\ *Corresponding author.Email:2779227378@qq.com
}

\begin{abstract}
The important role of data resources in the production of power has realized the reconstruction of the power relationship between the government, market and social organizations in the era of big data. This power reconstruction can be explained from three aspects: At the macro level, it is manifested in the optimization of power relations and a new round of concentration of power; At the meso level, it is the erosion and reconstruction of the government's power base; At the micro level, it is the great satisfaction of public rights and the wanton infringement of privacy rights.
\end{abstract}

Keywords: big data era, power reconstruction, power relations

\section{INTRODUCTION}

The market-oriented reforms since the reform and opening up have deconstructed the state's omnipotent political form. However, due to the government's absolute possession of the country's material resources, the past market-oriented reforms did not really touch the foundation of government power. Entering the era of big data, the important role of data resources in power production and the establishment of the market's decisive role in resource allocation have made economic power and social power continue to increase. The government, market and society will be in a dynamic equilibrium. The social power system has been reconstructed. This kind of power reconstruction will in turn have an important impact on the power relationship between the government, the market, and society, as well as on individuals in society. This influence can be explained from three levels: macro, meso, and micro.

\section{MACRO LEVEL: OPTIMIZATION OF POWER RELATIONS AND A NEW ROUND OF CENTRALI-ZATION OF POWER}

From the perspective of the entire social power system, the reconstruction of power in the era of big data has given the market and social organizations the ability to influence government behavior. The power acquired based on the possession of data resources is constantly being produced and applied in the market and social fields, which is enough to influence or even change the political process. At the same time, activity spaces without the penetration of administrative powers generated on the basis of new data power continue to emerge. Political power will increasingly be affected by economic power, social power and their interaction. In this process, a dynamically balanced network power structure between the government, the market and social organizations will be generated. This means that when the government interacts with the market and social organizations, it will no longer be able to adopt the methods of administrative orders in the past. Instead, it will connect with the market and social organizations as an equal participant. ${ }^{[1]}$

The innovation of information transmission technology will bring about a more frequent and rapid flow of data between organizations, and close the ties between organizations. The new data information derived from the analysis of the original data will expand the existing data connection network between organizations. With the continuous deepening of close organizational ties and the continuous expansion of organizational network, the entire social system will be placed in a community based on data. This means that an organization's actions will not only affect its own organization, but will also have an effect on other organizations in the community. The drastic changes in the social external environment will also affect every individual in the organization network, creating more active interactions between organizations. Realizing the 
sharing of power, and then reaching the foundation for cooperative governance. Before the advent of the big data era, the three types of organizations, government, market, and society, showed obvious heterogeneous relationships. Government organizations are public, emphasizing the overall public interest, paying attention to the provision of social public services and the solution of public problems; Market organization has individuality, emphasizes individual interests, pays attention to the profit acquisition of the organization and changes in social supply and demand; Social organizations are group in nature, emphasizing group interests and paying attention to the struggle for group interests and social rights. Obviously, such clear organizational boundaries can no longer meet the needs of society: on the one hand, the high fluidity of data and the cross-border open sharing of information have provided the necessary technical conditions for the cooperative governance of organizations; on the other hand, the sudden changes in the social environment and the frequent occurrence of compound governance problems obviously cannot achieve effective social governance by relying on the power of a single organization. This objectively also calls for cooperative governance among organizations.

The power reconstruction in the era of big data has realized the optimization of the power relationship between government, market and society. The continuous production of data power inhibits the expansion of political power. The concentration of power achieved by the government through the possession of material wealth in the past was broken. In theory, with the increase in market and social power brought about by creative power and the relative weakening of the government's distributive power, the social power system will develop in a direction of equality, reciprocity, and decentralization. However, the successive exposure of "price discrimination based on big data" incidents by companies such as Ctrip and Didi shows that as the public becomes more dependent on the new activity space created by data power, a new round of power concentration is taking place. Political power has the characteristics of self-expansion and self-expansion. For the market and social power, this law still applies. ${ }^{[2]}$ The collection and analysis of behavioral data is the basis for the market and social organizations to obtain data power. For leading big data companies such as Baidu, Tencent, and Alibaba, with the continuous production of new data, the continuous improvement of data analysis methods, and the increasing dependence of the public, the influence and control capabilities of such organizations on society will continue to increase. Creative power will continue to be concentrated in such organizations. In other words, in the short term, the circulation of data and the transmission of information seem to achieve a dynamic balance of the social power system. But in the long run, as data continues to be concentrated in large organizations, the phenomenon of power monopoly still exists. The power sharing and decentralization advertised in the era of big data will not be easily realized. The 8020 rule of social wealth distribution in agricultural and industrial society still exists in the era of big data. How to curb the continuous concentration of data power and prevent excessive abuse of power will obviously be an important task for the government in the future of big data governance.

\section{MESO LEVEL: EROSION AND RECONSTRUCTION OF THE GOVERNMENT POWER BASE}

The reconstruction of power in the era of big data makes data an important source of power. The dominant power acquired by the government through material wealth resources is gradually replaced by the creative power produced by the market and social organizations through the collection and analysis of data resources. At the same time, in contrast to the market and social organizations adopting active countermeasures in the era of big data and firmly grasping the development opportunities brought by the information revolution, government organizations still adopt the old stereotypes and thinking styles of the past, failing to recognize the importance of data for social change. With the increasing influence of economic power and social power, and infiltrating into the political realm, the power base of the government is gradually being eroded.

British writer George Orwell predicted in his novel Nineteen Eighty-Four that "information technology changes will enhance central planning and strengthen the monitoring power of the top level of the pyramid. Through a central database, computers can make the identification of the government and supervisors easier." The improvement of technical means really helps the top-level monitoring of the bottom-level. This prediction seems reasonable, but observing the reality of today's society, we can find that this prediction has not been fully realized. "The decentralization effect of computers has exceeded the concentration effect... Today's information rights are more widely distributed." The reason is that, on the one hand, the transformation of information technology not only empowers the government to monitor, but also enhances the ability of external government organizations to collect and transmit information, thereby bridging the information gap between the two. This means that while the government uses information technology to monitor society, it will also be subject to real-time supervision from external organizations. On the other hand, although the government has a huge central database, it involves policy, administration, economy and other aspects. But these massive data resources exist in fragments in governments at all levels, and are regarded as private property by governments at all levels and "hidden in the 
boudoir", focusing only on the preservation of data and ignoring the use of data. Although data is an important source of power, the real realization of power production is the effective mining and analysis of massive data. In other words, data that cannot be shared within the government will only form fragmented "information islands", and cannot form the government's overall data power, and the government's creative power will not be discussed. In the era of big data, the market and social organizations that master information tools and information capabilities will gradually realize the control of social reality, but the government can only passively respond to social needs by following the regulatory thinking of agricultural and industrial society. In the reality that the market and social power continue to erode political power, the government has long been imminent in rebuilding the power base centered on data.

\section{MICRO LEVEL: THE GREAT SATISFACTION OF PUBLIC RIGHTS AND THE WANTON INFRINGE-MENT OF PRIVACY RIGHTS}

From the micro-individual level, citizens in the era of big data are undoubtedly the biggest beneficiaries of technological change. As the governing body, the disclosure of government information and government data satisfy the public's right to know. The establishment of an online public opinion platform satisfies the public's right of participation and expression. The rapid flow and transmission of network information and data satisfies the public's right of supervision. In the process of continuous satisfaction of public rights, the subjective consciousness of citizens is constantly awakened. The technological change in the era of big data has realized the transformation of the public from the marginal to the core of governance. As a governance object, the market organization in the era of big data adheres to the customer-centric concept. Through the collection, integration and analysis of Internet customer behavior data, it is combined with corporate marketing strategies to provide customers with high-quality personalized services. While maximizing profits, it also meets the individual needs of customers. Governments and social organizations build a scientific decision-making system through the composition of Internet users and the characteristics of their network behavior, which improves the quality of services and facilitates the daily life of the public. All in all, the innovation of information and communication technology in the era of big data and the wide application of big data analysis technology have created and expanded people's production and living spaces, so that the people-centered development idea can be implemented.

Just as coins have both pros and cons, technological changes in the era of big data have not only brought great convenience to people, but also been accompanied by wanton infringements on citizens' privacy. When discussing the risk society, Baker asserted that "the most influential new technologies of the 21 st century hide significant undiscovered risks...but it is obvious that we hardly realize this." Therefore, Baker emphasized that "free application of scientific and technological achievements is bound to be impractical and undesirable." Although the reflection on the negative effects of technology has been around for a long time, it obviously has not attracted enough attention. Today, the doubleedged sword effect of big data technology is gradually emerging: appropriate analysis of citizen behavior data helps to organize the provision of personalized services, so as to better meet the needs of the public. However, big data also has disadvantages such as the invisibility of property rights and the uncertainty of ownership. In the era of big data, personal data information is often concentrated without the person's knowledge, and users will face a complete loss of control over their personal information. If data with both high liquidity and high derivability is abused, there is a danger of infringing on personal interests. In recent years, the frequent occurrence of price discrimination based on big data incidents shows that big data technology that should "know you but not you" is evolving into a profit tool for enterprises to "know you and use you". After analyzing customers' ability to pay and consumption preferences, some companies will provide the same service at different prices for different customers and different situations. This not only violates the basic principles of enterprise honesty and trustworthiness, but also violates the Anti-Monopoly Law and constitutes price discrimination. ${ }^{[3]}$ As customers' trust in Internet business activities continues to decrease, this will in turn endanger the development of the industry and even hinder technological progress.

There are three main reasons for the wanton infringement of big data technology on citizens' privacy rights. ${ }^{[4]}$ Firstly, enterprises are important owners of citizen behavior data, and naturally they are also important subjects that violate citizen information data. Internet companies generally lack the awareness of protecting citizens' personal information. Through technologies such as big data and cloud computing, the centralized production, flow and application of data are realized. After an effective analysis of user behavior preferences, guide and intervene in personal information acquisition and behavior selection. The ultimate goal of business organization is often to make profits. Under the dual pressure from competitors and shareholders in the same industry, business operators have difficulty setting and implementing strict user privacy protection policies consciously and voluntarily. Driven by commercial interests, the negative externalities of technical analysis are gradually revealed, which in turn derives vicious incidents that endanger citizen autonomy and information security, and even national information 
security. Secondly, the proliferation of data resources has also contributed to the strength of lawbreakers. "Technology allows ordinary individuals and groups to obtain the destructive power that was once mainly in the hands of the government." At the same time, "technology has also made contemporary complex social systems more vulnerable to large-scale attacks." It is different from the highly interactive strong connection that relies on blood relationship and clan family relationship in agricultural and industrial society. In the era of big data, with high-performance and low-cost information dissemination technology, it will be more of a weak connection between strangers and strangers. In a wide range of weak connections, although information can be transmitted more widely and conveniently, false information such as rumors will also spread rapidly in the social system, which will undoubtedly intensify the fragility of the social system. Third, in the case of widespread data leakage and abuse, although government regulatory agencies have the responsibility and obligation to protect citizens' privacy, they are also worried that the government's excessive administrative supervision will cause the industry to lose general prosperity, thereby causing the region, even the country has missed opportunities in economic competition. In fact, these three reasons have the same deep root, that is, industry supervision cannot be followed. With the rapid development of technology, the legal system of today's society is obviously unable to meet the needs. Therefore, building a complete legal system in the era of big data will be the only way to standardize the development of the industry and effectively protect the privacy of citizens.

\section{CONCLUSION}

The reconstruction of power in the era of big data and its impact have put forward higher requirements on the governance capabilities of the government. The government should actively respond to the positive effects of the optimization of the power relationship between the government, the market and the society and the great satisfaction of civil rights brought about by the power reconstruction. Provide the necessary institutional guarantees to maximize its positive impact. The government should also pay attention to issues such as the new round of centralization of power brought about by the reconstruction of power and the infringement of citizens' right to privacy, strengthen supervision functions, and standardize the operation of power in the era of big data. In addition, for the erosion of the government's power base by the market and social power, the government must also establish a data mindset and strengthen its own construction to rebuild the government's data power base.

\section{REFERENCES}

[1] Alemany Oliver, M., Vayre, J . Big data and the future of knowledge production in marketing research: Ethics, digital traces, and abductive reasoning. J Market Anal 3, 2015, pp.5-13.DOI: https://doi.org/10.1057/jma.2015.1

[2] Strang, K.D., Sun, Z. Big Data Paradigm: What is the Status of Privacy and Security?. Ann. Data. Sci. 4 ,

2017,pp.1-17.DOI: https://doi.org/10.1007/s40745-016-0096-6

[3] Casanovas, P., De Koker, L., Mendelson, D. et al. Regulation of Big Data: Perspectives on strategy, policy, law and privacy. Health Technol.2017,pp.335-349.DOI: https://doi.org/10.1007/s12553-017-0190-6

[4] Ducange, P., Pecori, R. \& Mezzina, P. A glimpse on big data analytics in the framework of marketing strategies. Soft Comput 22,2018,pp.325-342.DOI: https://doi.org/10.1007/s00500-017-2536-4 